\title{
Adherence to Mediterranean diet in athletes: a narrative review
}

\author{
Patrizia Calella $^{1}$ - Francesca Gallè ${ }^{1}(1) \cdot$ Valeria Di Onofrio ${ }^{2} \cdot$ Giuseppe Cerullo $^{1} \cdot$ Giorgio Liguori $^{1} \cdot$ Giuliana Valerio $^{1}$
}

Received: 8 June 2021 / Accepted: 17 January 2022 / Published online: 2 February 2022

(c) The Author(s) 2022

\begin{abstract}
Athletes' diet should be adequate both in quality and quantity, to avoid deficiencies and limit fatigue. In recent years, several nutritional recommendations have been published and a multitude of diets based on empirical approaches have been employed in the sport setting. In the last decades, the Mediterranean diet (MD) has been extensively studied for its beneficial effects on health but its adoption in athletes has never been critically analyzed. This review was aimed to assess the current literature about the athletes' adherence to the MD pattern, also in comparison with the general population. The majority of the studies show that athletes reach a mean level of MD adherence, higher than that of the general population. However, the current evidence is still limited and based on studies using different methods. Further research is needed to better characterize this habit among athletes.
\end{abstract}

Keywords Sport $\cdot$ Athletes $\cdot$ Mediterranean diet $\cdot$ Nutrient intake

\section{Introduction}

An appropriate nutrition is essential for athletes. The consumption of a balanced diet contributes to enhance athletic performance and optimize training adaptations [1]. Athletes' diet should be adequate both in quality and quantity, to avoid deficiencies, limit fatigue and replenish the energy reserves. Athletic performance is indeed determined by the intake of macronutrients and micronutrients, and by the availability of stored energy substrates to power muscle contraction

Francesca Gallè

francesca.galle@uniparthenope.it

Patrizia Calella

patrizia.calella@uniparthenope.it

Valeria Di Onofrio

valeria.dionofrio@uniparthenope.it

Giuseppe Cerullo

giuseppe.cerullo@uniparthenope.it

Giorgio Liguori

giorgio.liguori@uniparthenope.it

Giuliana Valerio

giuliana.valerio@uniparthenope.it

1 Department of Movement Sciences and Wellbeing, University of Naples Parthenope, 80133 Naples, Italy

2 Department of Sciences and Technologies, University of Naples Parthenope, 80143 Naples, Italy
[2]. Furthermore, a well-balanced diet may support athletes' immune system function, moderate inflammation and enhance recovery and injury repair $[3,4]$.

Balancing energy and macronutrient intake with expenditure is crucial to reach the optimal body composition goal and to support training and performance [5-7]. Furthermore, micronutrients are involved in numerous biological processes which are relevant for exercise and athletic performance, such as oxygen transport, energy utilization, inflammation, protein and bone metabolism, and immune function $[1,8,9]$.

The interest toward sport nutrition as a specialized discipline has risen in the last decades. Accordingly, sport nutrition recommendations are evolving in parallel with the latest scientific evidence $[1,2,10]$.

In the last few years, several scientific societies released their recommendations on sport nutrition, namely the International Society of Sports Nutrition (ISSN), the Academy of Nutrition and Dietetics, Dietitians of Canada, and the American College of Sports Medicine (ADA-ACSM), and the Sports Dieticians Australia (SDA) [1, 2, 10]. Generally, these documents are focused on the appropriate amount and timing of nutrient, fluid, and supplement intake to promote the optimal performance in the different sports disciplines.

Despite the importance of good nutrition for health and performance, evidence shows that athletes do not always meet sport nutritional recommendations [11-14]. In particular, 
energy and carbohydrate intakes seem to be insufficient, while proteins are adequate or higher than recommended in team sport athletes; fat intakes are lower than recommended in strength sports and unbalanced in team sport with a tendency towards an unhealthy use of saturated fats [11-14].

It is of concern that in the sport setting, diet is often addressed to enhance performance or esthetic aspects rather than health [15], and athletes may be at risk of moving away from healthy diet patterns to achieve specific goals, which may lead them to develop negative health consequences [16-18].

In the last decades, the Mediterranean diet (MD) has been extensively studied for its nutritional adequacy and its beneficial effects on health [19]. This dietary pattern, resembling the traditional eating habits of people from the Mediterranean area during the $60 \mathrm{~s}$, is characterized by a low intake of cholesterol and trans-fatty acids for an infrequent consumption of butter, cream, sweets and red meat; a frequent intake of monounsaturated fatty acids derived from olive oil; a virtuous intake of poly-unsaturated fatty acids through the frequent consumption of fish; a worthy quantity of fibers, minerals, vitamins and polyphenols due to the regular consumption of non-refined cereals, legumes, vegetables, fruits and nuts. Close adherence to MD (AMD) makes the risk of deficient mineral intake quite improbable; the mineral contribution of MD to the daily intake may be considered as moderate for potassium and zinc, and high for phosphorus, magnesium, iron, sodium, and copper. Lastly, bioactive compounds such as flavonols are provided by a moderate consumption of red wine in adults $[19,20]$. The positive effects of MD do not derive by the consumption of a single food, but from the synergic effect of different components. For instance, the interaction between the adequate intake of poly-unsaturated fatty acids, as well as the high content in fibers, antioxidants and polyphenols has been associated with an overall better metabolic health [20, 21].

Several studies have highlighted the significant health benefits deriving from a high AMD in the general population of children and adults [21-23]. Furthermore, there is also evidence that healthy dietary habits, such as the adherence to the MD model, are associated with an active lifestyle [24]. However, little is known about the AMD in athletes.

On the basis of these considerations, this overview was aimed to analyze the available evidence regarding the athletes' AMD, in the perspective of evaluating its promotion as a healthy dietary pattern in the sport setting.

\section{Search strategy}

Peer-reviewed literature listed in PubMED, Google Scholar, SPORTDiscus and Prospero electronic databases was searched up to September 2021. Search was performed using the following keywords: 'athletes/sport/athletics' and 'Mediterranean DIet' and limited to the English, Italian, French and Spanish language. All search terms were combined within each keyword by the Boolean command OR, and the keywords (and respective search terms) were linked by the Boolean command AND.

Criteria for inclusion of the articles were: 1 . The population of interest consists of athletes (individuals practicing sports at any level) of any age and gender. 2. AMD evaluated with validated assessment tool. 3 . The article presents an original study. Cross-sectional, prospective, and retrospective studies are considered. Reviews are included to identify further references.

All the studies identified through the search strategy were imported in a Microsoft Excel database and duplicates were removed. Potentially relevant articles were identified independently by three authors (PC, FG and VDO) through the initial screening of titles and abstracts. Then, full text articles were assessed independently for eligibility by two authors (PC and VDO). Conflicts regarding the inclusion or exclusion of articles were resolved by a third author (FG).

Data related to the study information (author, year, country, study population and design, sample size, age, gender, type and level of sport, control group), MD adherence assessment tool and results were extracted from the selected articles by three authors (PC, FG and VDO).

\section{Results}

A total of 26,143 records were initially found. After the removal of duplicates and the screening process, 61 full text articles were assessed for eligibility. At the end of the selection, 16 studies were included in the analysis [25-40]. Figure 1 shows the phases of the selection procedure.

The characteristics of the studies included are summarized in Table 1. All the studies were performed in Mediterranean countries, mainly in Spain $(n=13)$. Fifteen studies were cross-sectional; five specifically involved cyclists [28, $32-34,39]$. Three studies [25, 32, 36] involved only females, while one study involved only males [29], two studies [28, $39]$ did not specify sex proportion. Seven investigations were carried out among adolescents [25, 27, 29, 35, 37-39], one study involved both adolescents and adults [30], while the others regarded adults.

Six different tools, validated in previous studies, were used to assess the level of AMD pattern: the Mediterranean Adequacy Index (MAI), employed in one study [25]; the KIDMED questionnaire, used in nine studies [27, 29-31, 35-38, 40]; the Mediterranean Diet Score (MDS), used in one study [40]; the Mediterranean Adherence Diet Screener (MEDAS), employed in other three studies [27, 32, 34]; the 


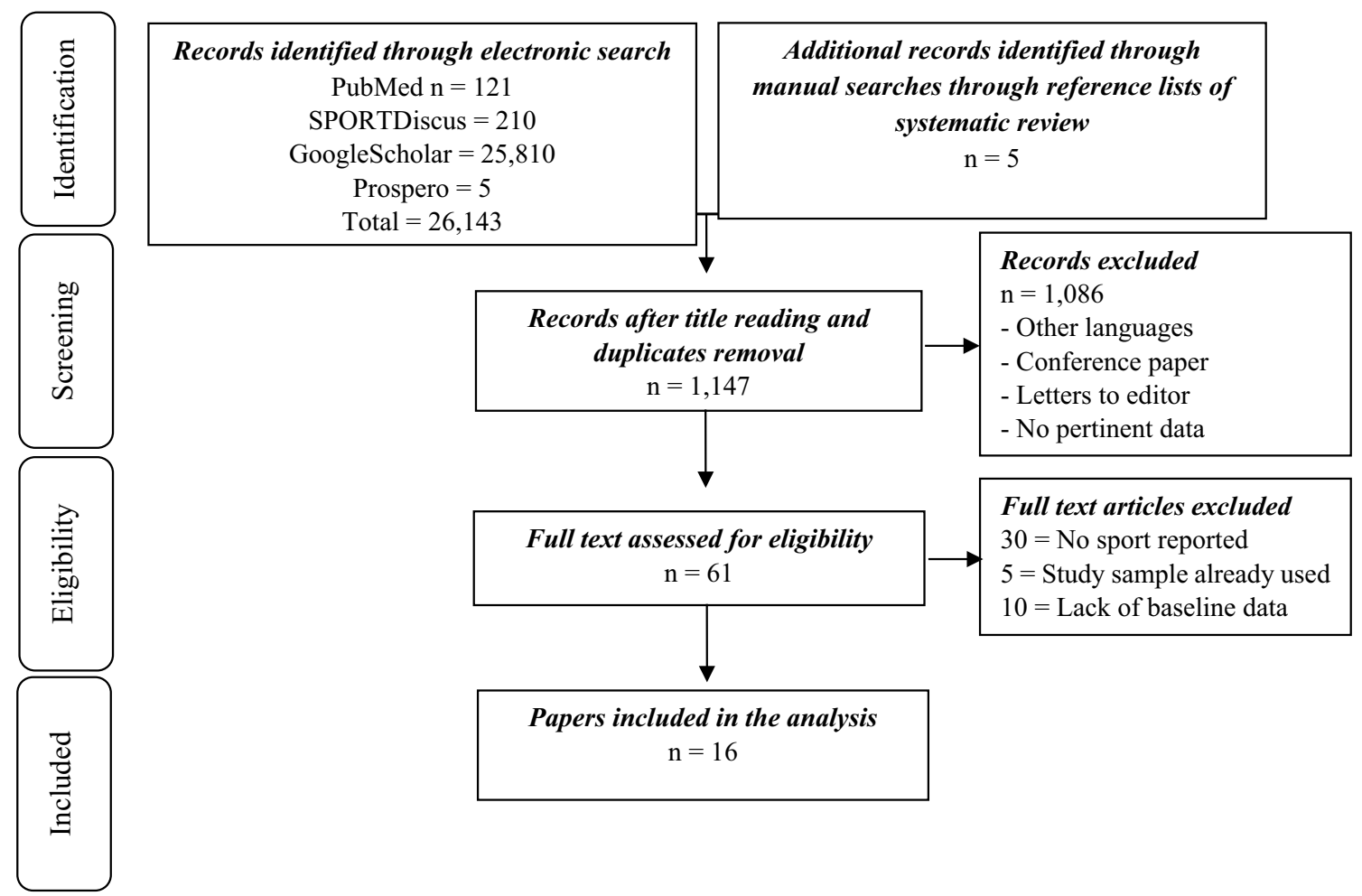

Figure. 1 Flow chart of the literature search strategy

PREDIMED, used in one study [28] and the Mediterranean Diet Adequacy Score (MDAS) in another study [26].

In the majority of the studies, the athletes' dietary habits were classified as averagely adherent to the MD. Three articles reported poor AMD [25, 36, 40] and two studies reported good AMD [25, 27] in a part of the samples examined.

Of the 10 studies that included both males and females, only 7 analyzed the gender differences in AMD [19, 20, 25, 29, 31-33]. Three found a significantly higher score in women ( 2 using the MEDAS and 1 the MDAS), [19, 31, 33], and one study found greater adherence in males (using MDS), [25]. The other studies did not show significant differences in AMD between the two genders, [20, 29, 32].

Furthermore, taking into consideration the level of competition of the athletes, studies that included professional athletes [26, 28, 35, 36, 39] did not demonstrate any differences in AMD between amateur or semi-professional athletes.

Regarding the survey tools employed, the only study using MAI [24] found, in a group of Spanish cyclists a low score of AMD. Nine studies used KIDMED [18, 20-23, 26, 28-30] and reported a medium AMD in the whole study sample. One study found the lowest percentage of subjects with low AMD (1\%) and the highest percentage of high adherence in female kayakers (57\%) [18]. On the contrary, Rubio et al. found that the $58 \%$ of young football players had a low AMD [21]. Three studies used MEDAS in an adult population of cyclists and encountered a medium AMD in the analyzed groups, except for Munguia et al. which found a high AMD value in women [32]. Citarella et al. used the MDAS in a population of adult ultra-marathon runners reporting a medium AMD [19], and the same result was obtained by Gabaldon et al. using the PREDIMED questionnaire, in young adult cyclists, swimmers, and basketball players [27]. Del Rio et al. registered a low AMD using MDS questionnaire in a sample of basketball and badminton adult players [25].

The athletes' AMD pattern was higher than controls or the general population in all the studies $[25,27,28,32-34$, 38-40] which included a similar comparison. These studies used different tools to assess the MD adherence (MAI, KIDMED, MDS, MEDAS, PREDIMED). Only Santana et al. found that AMD was lower in girls who performed rhythmic gymnastics than the reference population, while it was higher in adolescent gymnasts than non-athletes [38].

\section{Discussion and conclusions}

This review was aimed to analyze the adherence to the MD pattern in the sport setting. The results of our analysis show that the majority of the available studies reported a medium athletes' adherence to MD. Interestingly, in these studies 


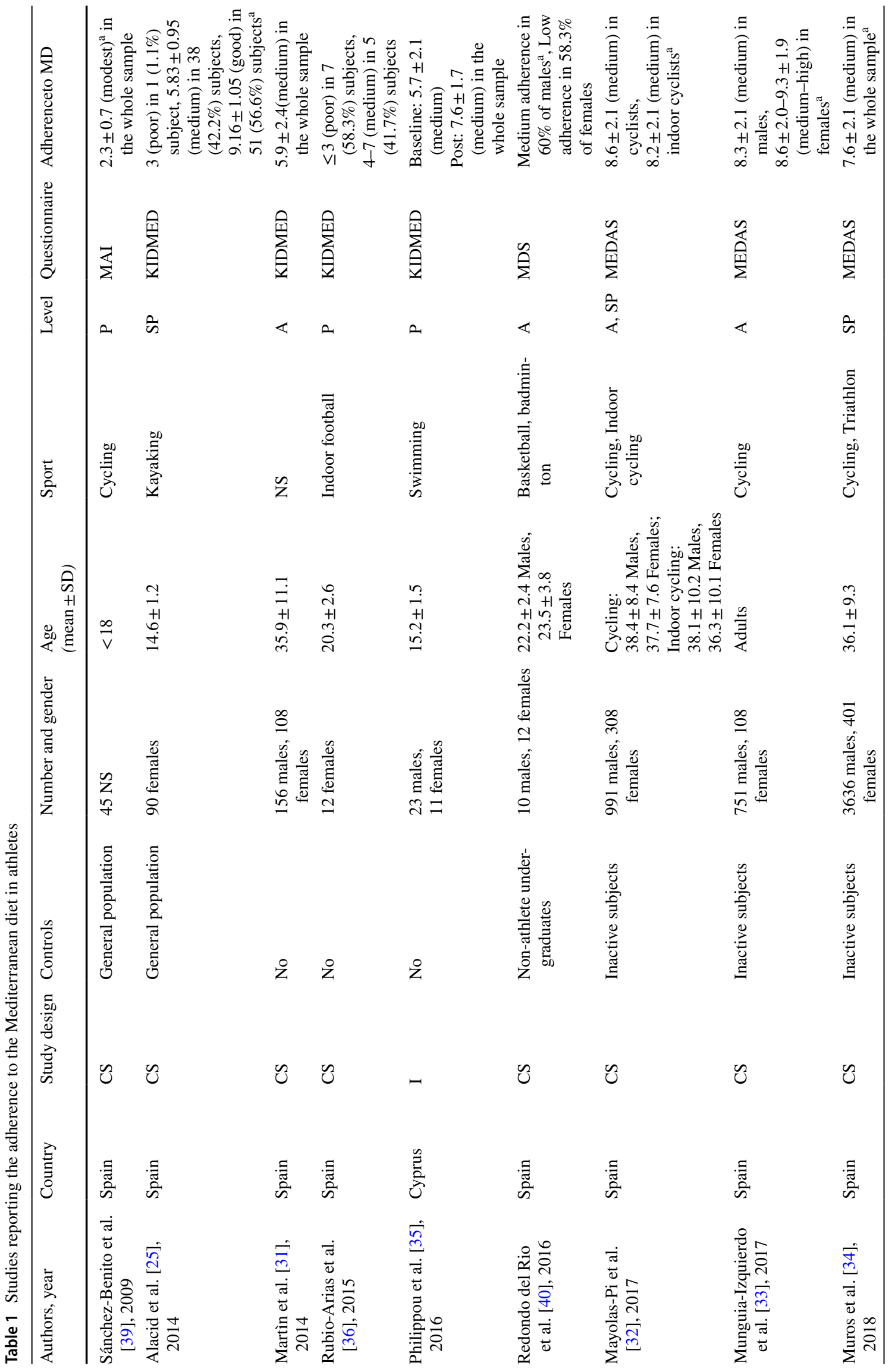




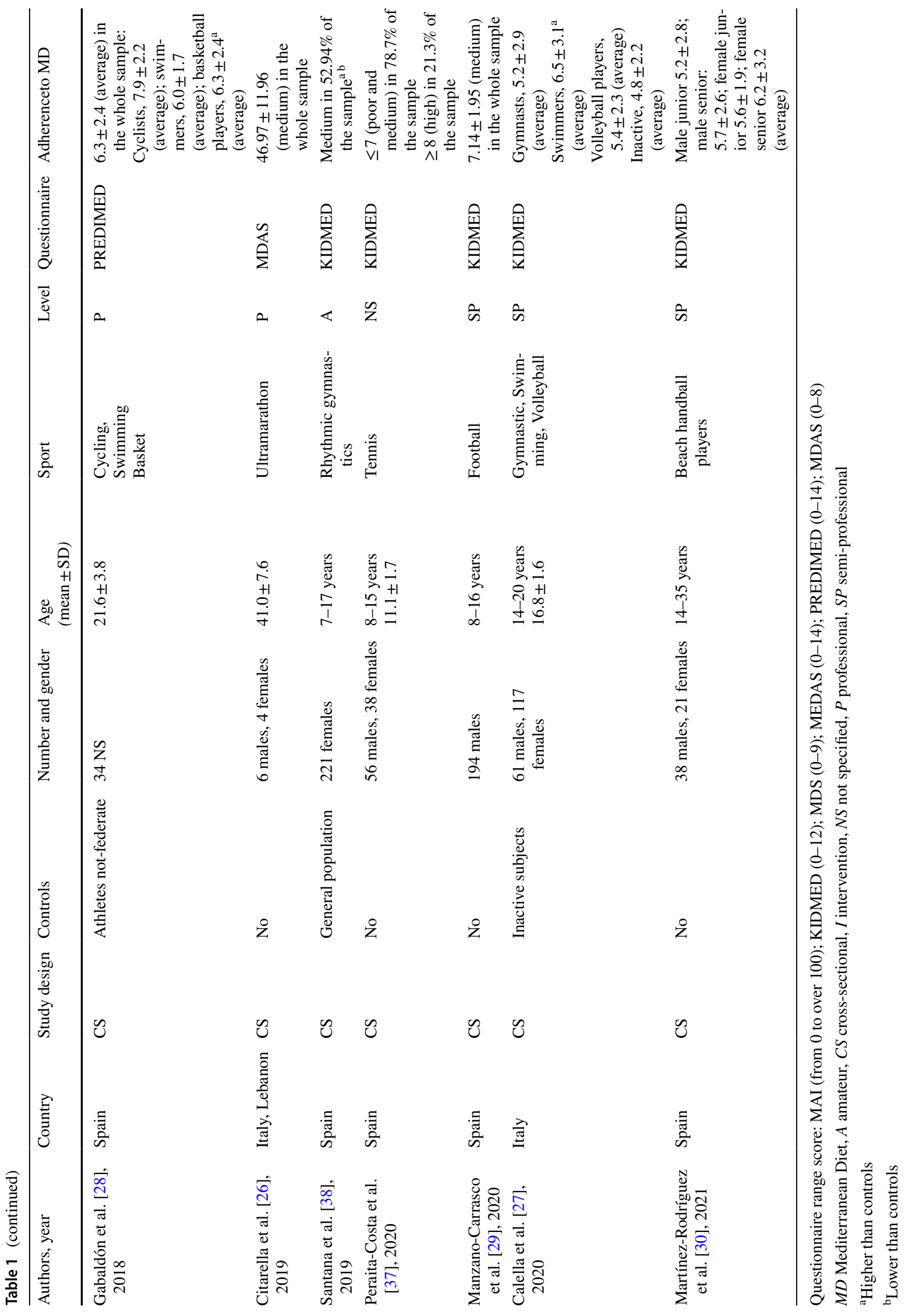


athletes seem to follow the MD pattern to a greater extent than their inactive controls and the general population. Furthermore, our analysis showed that despite the different sports, also practiced at different levels, in subjects of different age groups and of both genders, there were no differences in AMD.

This suggests that MD model is practiced by athletes and its feasibility as a healthy dietary pattern in sport nutrition could be properly considered. This consideration can be done on the light of the basic elements which traditionally characterize the MD pattern. First of all, due to its richness in vegetables and fruits, it could be a natural strategy to get the right amount of minerals and vitamins and avoid the use of supplements which is very common in athletes (between 40 and 100\% depending on the type of sport and competition level) [41]. Further, MD may assure an optimal supply of antioxidants, such as tocopherols, carotenoids and polyphenols [42], that improve antioxidant defense and counteract oxidative stress induced by intense and prolonged physical exercise [43] better than other supplement-based approaches [44]. In fact, supplementation with high doses of antioxidants may inhibit the generation of reactive oxygen species during vigorous exercise and negatively affect the adaptations induced by exercise and the athletic performance [45]. On the contrary, the adoption of a balanced diet rich in fruits and vegetables as provided by the MD model represents the best approach to maintain an optimal mineral intake and antioxidant status and counteract the oxidative stress [46-48].

Moreover, MD offers multiple possibilities of modulation and customization according to the individual needs, to comply with specific sport nutrition recommendations. The transferability of the traditional MD pattern to non-Mediterranean populations is also possible due to its nutritional adequacy, palatability, potential for health and sustainability [49].

Nutrition knowledge, healthy food habits and adherence to the MD pattern are strictly related in athletes [27, 50]. Therefore, providing them with nutritional education about the beneficial effects of MD and recommendations tailored to type of sport, volume of training, body composition, hydration status, food allergies or other special needs, may be a useful strategy to improve athletes' health and performance.

Our review highlights that the MD pattern is quite diffused in sport setting, suggesting that it can be actually suitable to sustain athletes' needs and that its adoption may be determined by the close attention athletes pay to diet. However, it should be noted that the evidence analyzed in this review comes from studies conducted in Mediterranean countries, whose populations traditionally show higher levels of AMD than the non-Mediterranean ones [51]. Whether the MD can be adopted in non-Mediterranean countries has been a topic of discussion among health professionals. Emerging evidence suggests that this is achievable [52]. With regards to this aspect, it should be noted that in recent analyses the increased availability of non-Mediterranean foods-such as vegetable oils, sugar, sweeteners and meat, have been recognized as contributors to the deterioration of the MD pattern and to the increased conformity of dietary habits observed worldwide in the last decades. Therefore, it would be interesting to explore in depth AMD and its determinants in athletes from different geographical areas, in order to evaluate if our findings are related with athletes' awareness and conscious choices or due to cultural, traditional reasons or even to the availability of foods typically included in the MD pattern.

Furthermore, it should be considered that seven different questionnaires were used in the examined studies. Even though a medium AMD was mostly reported by using the KIDMED questionnaire, and a general consistence was found, comparing results from studies using different tools is not quite right. Furthermore, as revealed by a recent systematic review, psychometric properties and transcultural adaptation of the tools used for evaluating AMD may weaken their validity [53].

Our overview underlines that literature analyzing MD adherence in athletes is still scarce and the available information do not allow to draw clear conclusions. The examined investigations were carried out only in few Mediterranean countries, mainly in Spain, and referred to few sport disciplines, mainly cycling. Moreover, the use of different questionnaires hindered the comparison of the results. Further studies extended to a wider range of sports and based on the same investigation tool are needed to better characterize this issue. Furthermore, the adherence to the MD pattern showed by athletes from different countries-Mediterranean and possibly non-Mediterranean countries-should be evaluated to highlight its potential socio-cultural determinants. Besides, evidence is still lacking about the ability of MD in supporting specific performance-related requirements.

In conclusion, this review shows an average adherence to MD in athletes living in Mediterranean countries and highlights higher levels of MD adherence in athletes respect to inactive subjects and to the general population. As the adherence to the MD model has shown a decrease in the general population, these results show that this dietary pattern is still preserved in this category [51]. This suggests that MD promotion may be implemented in the sport setting, in order to help athletes in maintaining their health and supporting their nutritional needs. However, the limited number of available studies and populations examined and the heterogeneity of the research methods require caution in the generalization of these findings. 


\section{Declarations}

Conflict of interest The authors report no conflicts of interest and certify that no funding has been received for this study and/or preparation of this manuscript.

Ethical approval Not applicable.

Consent to participate Not applicable.

Open Access This article is licensed under a Creative Commons Attribution 4.0 International License, which permits use, sharing, adaptation, distribution and reproduction in any medium or format, as long as you give appropriate credit to the original author(s) and the source, provide a link to the Creative Commons licence, and indicate if changes were made. The images or other third party material in this article are included in the article's Creative Commons licence, unless indicated otherwise in a credit line to the material. If material is not included in the article's Creative Commons licence and your intended use is not permitted by statutory regulation or exceeds the permitted use, you will need to obtain permission directly from the copyright holder. To view a copy of this licence, visit http://creativecommons.org/licenses/by/4.0/.

\section{References}

1. Kerksick CM, Wilborn CD, Roberts MD et al (2018) ISSN exercise \& sports nutrition review update: research \& recommendations. J Int Soc Sports Nutr 15:38. https://doi.org/10.1186/ s12970-018-0242-y

2. Thomas DT, Erdman KABL (2016) Position of the academy of nutrition and dietetics, dietitians of Canada, and the American college of sports medicine: nutrition and athletic performance. $\mathrm{J}$ Acad Nutr Diet 116:501-528. https://doi.org/10.1249/MSS.00000 00000000852

3. Marcos A, Nova E, Montero A (2003) Changes in the immune system are conditioned by nutrition. Eur J Clin Nutr 57:S66-S69. https://doi.org/10.1038/sj.ejcn.1601819

4. Bruunsgaard H (2005) Physical activity and modulation of systemic low-level inflammation. J Leukoc Biol 78:819-835. https:// doi.org/10.1189/jlb.0505247

5. Burke LM, Loucks AB, Broad N (2006) Energy and carbohydrate for training and recovery. Nutr Footb FIFA/FMARC Consens Sport Nutr 24:675-685. https://doi.org/10.4324/9780203967430

6. Burke LM (2001) Energy needs of athletes. Can J Appl Physiol 26:S202-S219

7. Manore MM (2015) Weight management for athletes and active individuals: a brief review. Sport Med 85:83-92. https://doi.org/ 10.1007/s40279-015-0401-0

8. Speich M, Pineau A, Ballereau F (2001) Minerals, trace elements and related biological variables in athletes and during physical activity. Clin Chim Acta 312:1-11. https://doi.org/10.1016/ S0009-8981(01)00598-8

9. Williams M (2007) Dietary supplements and sports performance: minerals. J Int Soc Sports Nutr 3:43-49. https://doi.org/10.1186/ 1550-2783-3-1-1

10. Burke LM, Castell LM, Casa DJ et al (2019) International association of athletics federations consensus statement 2019: nutrition for athletics. Int J Sport Nutr Exerc Metab 29:73-84. https://doi. org/10.1123/ijsnem.2019-0065
11. Wardenaar F, Brinkmans N, Ceelen I et al (2017) Micronutrient intakes in 553 dutch elite and sub-elite athletes: prevalence of low and high intakes in users and non-users of nutritional supplements. Nutrients. https://doi.org/10.3390/nu9020142

12. Spendlove J, Mitchell L, Gifford J et al (2015) Dietary Intake of competitive bodybuilders. Sport Med 45:1041-1063. https://doi. org/10.1007/s40279-015-0329-4

13. Jenner B, Belski, et al (2019) Dietary intakes of professional and semi-professional team sport athletes do not meet sport nutrition recommendations - a systematic literature review. Nutrients 11:1160. https://doi.org/10.3390/nu11051160

14. García PMR, García-Zapico P, Patterson ÁM, Iglesias-Gutiérrez E (2014) Nutrient intake and food habits of soccer players: analyzing the correlates of eating practice. Nutrients 6:2697-2717. https:// doi.org/10.3390/nu6072697

15. Westberg K, Stavros C, Parker L et al (2021) Promoting healthy eating in the community sport setting: a scoping review. Health Promot Int. https://doi.org/10.1093/heapro/daab030

16. Logue DM, Madigan SM, Melin A et al (2020) Low energy availability in athletes 2020: on sports performance. Nutrients 12:1-19

17. Melin AK, Heikura IA, Tenforde A, Mountjoy M (2019) Energy availability in athletics: health, performance, and physique. Int J Sport Nutr Exerc Metab 29:152-164. https://doi.org/10.1123/ ijsnem.2018-0201

18. Tipton KD (2011) Efficacy and consequences of very-high-protein diets for athletes and exercisers. Proc Nutr Soc 70:205-214. https://doi.org/10.1017/S0029665111000024

19. Martinez-Lacoba R, Pardo-Garcia I, Amo-Saus E, EscribanoSotos F (2018) Mediterranean diet and health outcomes: a systematic meta-review. Eur J Public Health 28:955-961. https:// doi.org/10.1093/eurpub/cky113

20. Davis C, Bryan J, Hodgson J, Murphy K (2015) Definition of the mediterranean diet: a literature review. Nutrients 7:9139-9153. https://doi.org/10.3390/nu7115459

21. Dinu M, Pagliai G, Casini A, Sofi F (2018) Mediterranean diet and multiple health outcomes: an umbrella review of metaanalyses of observational studies and randomised trials. Eur $\mathbf{J}$ Clin Nutr 72:30-43. https://doi.org/10.1038/ejcn.2017.58

22. Iaccarino Idelson P, Scalfi L, Valerio G (2017) Adherence to the Mediterranean diet in children and adolescents: a systematic review. Nutr Metab Cardiovasc Dis 27:283-299. https://doi.org/ 10.1016/j.numecd.2017.01.002

23. Sofi F, Macchi C, Abbate R et al (2013) Mediterranean diet and health status: an updated meta-analysis and a proposal for a literature-based adherence score. Public Health Nutr 17:27692782. https://doi.org/10.1017/S1368980013003169

24. Fransen HP, Boer JMA, Beulens JWJ et al (2016) Associations between lifestyle factors and an unhealthy diet. Eur J Public Health 27:190. https://doi.org/10.1093/eurpub/ckw190

25. Alacid F, Vaquero-Cristóbal R, Sánchez-Pato A, Muyor JMLMP (2014) Habit based consumptions in the mediterranean diet and the relationship with anthropometric parameters in young female kayakers. Nutr Hosp 29:121-127. https://doi.org/10. 3305/nh.2014.29.1.6995

26. Citarella R, Itani L, Intini V et al (2021) Association between dietary practice, body composition, training volume and sport performance in $100-\mathrm{Km}$ elite ultramarathon runners. Clin Nutr ESPEN 42:239-243. https://doi.org/10.1016/j.clnesp.2021.01. 029

27. Calella P, Gallè F, Di Onofrio V et al (2020) Gym members show lower nutrition knowledge than youth engaged in competitive sports. J Am Coll Nutr. https://doi.org/10.1080/07315724.2020. 1792375

28. Gabaldón P, Pedro R, Peris G et al (2018) Estudio Nutri-K : Evaluación de la ingesta de potasio y el deporte en adultos jóvenes 
Nutri-K study: evaluation of potassium intake and sport in young adults. Nutr Clín Diet Hosp. https://doi.org/10.12873/383romeu

29. Manzano-Carrasco S, Felipe JL, Sanchez-Sanchez J et al (2020) Physical fitness, body composition, and adherence to the Mediterranean diet in young football players: influence of the $20 \mathrm{msrt}$ score and maturational stage. Int J Environ Res Public Health 17:3257. https://doi.org/10.3390/ijerph17093257

30. Martínez-Rodríguez A, Martínez-Olcina M, Hernández-García M et al (2021) Mediterranean diet adherence, body composition and performance in beach handball players: a cross sectional study. Int J Environ Res Public Health 18:2837. https://doi.org/10.3390/ijerp h18062837

31. Martín ISM, Vilar EG, Fernández MG et al (2014) Hábitos alimentarios y psicológicos en personas que realizan ejercicio físico. Nutr Hosp 30:1324-1332. https://doi.org/10.3305/nh.2014.30.6. 7838

32. Mayolas-Pi C, Munguia-Izquierdo D, Peñarrubia-Lozano $\mathrm{C}$ et al (2017) Adherence to the Mediterranean diet in inactive adults, indoor cycling practitioners and amateur cyclists. Nutr Hosp 35:131-139. https://doi.org/10.20960/nh.1099

33. Munguia-Izquierdo D, Mayolas-Pi C, Peñarrubia-Lozano $\mathrm{C}$ et al (2017) Effects of adolescent sport practice on health outcomes of adult amateur endurance cyclists: adulthood is not too late to start. J Phys Act Heal. https://doi.org/10.1123/jpah.2017-0010

34. Muros JJ, Zabala M (2018) Differences in Mediterranean diet adherence between cyclists and triathletes in a sample of Spanish athletes. Nutrients. https://doi.org/10.3390/nu10101480

35. Philippou E, Middleton N, Pistos C et al (2017) The impact of nutrition education on nutrition knowledge and adherence to the Mediterranean diet in adolescent competitive swimmers. J Sci Med Sport 20:328-332. https://doi.org/10.1016/j.jsams.2016.08. 023

36. Rubio-Arias JÁ, Ramos Campo DJ, Ruiloba Nuñez JM, Carrasco Poyatos M, Alcaraz Ramón PE, JDF, (2015) Adherence to a Mediterranean diet and sport performance in a elite female athletes futsal. Nutr Hosp 3131:2276-2282. https://doi.org/10.3305/nh. 2015.31.5.8624

37. Peraita-Costa I, Llopis-Morales A, Marí-Bauset S et al (2020) Burnout syndrome risk in child and adolescent tennis players and the role of adherence to the Mediterranean diet. Int J Environ Res Public Health 17:929. https://doi.org/10.3390/ijerph17030929

38. Santana MV, Mirón IM, Vargas LA, Bedoya JL (2019) Comparative analysis of adherence to the Mediterranean diet among girls and adolescents who perform rhythmic gymnastics. Rev Bras Med do Esporte. https://doi.org/10.1590/1517-869220192504175283

39. Sánchez-Benito JL, Sánchez-Soriano E, Ginart Suárez J (2009) Assessment of the Mediterranean diet Adequacy Index of a collective of young cyclists. Nutr Hosp 24:77-86

40. Del Río MPR, Silleras BDM, Enciso LC et al (2016) Ingesta dietética y adherencia a la dieta mediterránea en un grupo de estudiantes universitarios en función de la práctica deportiva. Nutr Hosp. https://doi.org/10.20960/nh.583
41. Garthe I, Maughan RJ (2018) Athletes and supplements: prevalence and perspectives. Int J Sport Nutr Exerc Metab 28:126-138. https://doi.org/10.1123/ijsnem.2017-0429

42. Castro-Quezada I, Román-Viñas B, Serra-Majem L (2014) The Mediterranean diet and nutritional adequacy: a review. Nutrients 6:231-248. https://doi.org/10.3390/nu6010231

43. Rossi M, Caruso F, Kwok L et al (2017) Protection by extra virgin olive oil against oxidative stress in vitro and in vivo. Chemical and biological studies on the health benefits due to a major component of the Mediterranean diet. PLoS ONE 12:e189341. https://doi. org/10.1371/journal.pone.0189341

44. Dai J, Jones DP, Goldberg J et al (2008) Association between adherence to the Mediterranean diet and oxidative stress. Am J Clin Nutr 88:1364-1370. https://doi.org/10.3945/ajcn.2008.26528

45. Clarkson PM, Thompson HS (2000) Antioxidants: what role do they play in physical activity and health? Am J Clin Nutr 72:6375-6446

46. Mankowski RT, Anton SD, Buford TW, Leeuwenburgh C (2015) Dietary antioxidants as modifiers of physiologic adaptations to exercise. Med Sci Sports Exerc 47:1857-1868. https://doi.org/ 10.1249/MSS.0000000000000620

47. Maughan RJ, Depiesse F, Geyer H (2007) The use of dietary supplements by athletes. J Sports Sci 25:S103-S113. https://doi.org/ 10.1080/02640410701607395

48. Gomez-Cabrera MC, Domenech E, Viña J (2008) Moderate exercise is an antioxidant: upregulation of antioxidant genes by training. Free Radic Biol Med 44:126-131. https://doi.org/10.1016/j. freeradbiomed.2007.02.001

49. González-Martínez M, Hershey SM, Zazpe I, Trichopoulou A (2017) Transferability of the Mediterranean diet to non-Mediterranean countries. What is and what is not the Mediterranean diet. Nutrients 9:1226. https://doi.org/10.3390/nu9111226

50. Spronk I, Heaney SE, Prvan T, O'Connor HT (2015) Relationship between general nutrition knowledge and dietary quality in elite athletes. Int J Sport Nutr Exerc Metab 25:243-251. https://doi. org/10.1123/ijsnem.2014-0034

51. Vilarnau C, Stracker DM, Funtikov A et al (2019) Worldwide adherence to Mediterranean diet between 1960 and 2011. Eur J Clin Nutr 72:83-91. https://doi.org/10.1038/s41430-018-0313-9

52. Murphy KJ, Parletta N (2018) Implementing a Mediterraneanstyle diet outside the Mediterranean Region. Curr Atheroscler Rep 20:28. https://doi.org/10.1007/s11883-018-0732-z

53. Zaragoza-Martí A, Cabañero-Martínez M, Hurtado-Sánchez J et al (2018) Evaluation of Mediterranean diet adherence scores: a systematic review. BMJ Open 8:e019033. https://doi.org/10.1136/ bmjopen-2017-019033

Publisher's Note Springer Nature remains neutral with regard to jurisdictional claims in published maps and institutional affiliations. 